\title{
Single Step Synthesis of Amino-Functionalized Magnetic Nanoparticles with Polyol Technique at Low Temperature
}

\author{
Nut Songvorawit, ${ }^{1}$ Kooranee Tuitemwong, ${ }^{1}$ and Pravate Tuitemwong ${ }^{2}$ \\ ${ }^{1}$ Department of Microbiology, Faculty of Science, Kasetsart University, Bangkok 10900, Thailand \\ ${ }^{2}$ Risk and Decision Analysis Lab (RADAL), Food Safety Center, Department of Microbiology, Faculty of Science, \\ King Mongkut's University of Technology Thonburi (KMUTT), Bangkok 10140, Thailand
}

Correspondence should be addressed to Kooranee Tuitemwong, fscikrt@ku.ac.th and Pravate Tuitemwong, ptt59@hotmail.com

Received 17 March 2011; Accepted 1 May 2011

Academic Editor: B. Tan

Copyright (C) 2011 Nut Songvorawit et al. This is an open access article distributed under the Creative Commons Attribution License, which permits unrestricted use, distribution, and reproduction in any medium, provided the original work is properly cited.

The synthesis and characterization of amino-functionalized magnetic nanoparticles (amino-MNPs) were carried out. AminoMNPs were prepared using polyol technique in an autoclave $\left(121^{\circ} \mathrm{C}\right)$ without inert gas. The characterization of particles employed conventional SEM-EDS, TEM, XRD, FTIR, and VSM techniques. Results showed that amount of $\mathrm{NaOH}$ affected to the speed of MNP formation. The desirable uniform cubic shape of amino-MNPs was obtained from the addition of $2.50 \% \mathrm{w} / \mathrm{v} \mathrm{NaOH} \mathrm{for} 3$ reaction cycles ( 2 hours/cycle). The amino-MNPs obtained from this condition have cubic shapes with the average size of $43 \pm$ $9 \mathrm{~nm}$. Results from elemental and structure analyses confirmed that the product was pure magnetite. The magnetic properties were ferromagnetism and were very close to a complete superparamagnetism. Fourier transform infrared (FT-IR) spectrum showed that the amino group existed on particle surface. The amino-MNPs of cubic shape were synthesized with facile single step at low temperature, and they have potential to be used for rapid microbial detection and many biological applications.

\section{Introduction}

In the past few years, nanotechnology has opened up a new era in the development of labeling reagents for highly sensitive detection of diverse targets. Various nanoparticles are currently being developed to have physical, chemical, and biological properties which are unique and suitable for different applications.

Magnetic nanoparticles (MNPs) especially magnetite $\left(\mathrm{Fe}_{3} \mathrm{O}_{4}\right)$ and maghemite $\left(\gamma\right.$ - $\left.\mathrm{Fe}_{2} \mathrm{O}_{3}\right)$ nanoparticles are of interest in various biological applications such as contrast agent for magnetic resonance imaging (MRI), bacterial detection, drug delivery, hyperthermia, and magnetofection [1-5]. Since most of biological applications are conducted in aqueous phase, as such MNPs must have hydrophilic properties. To be appropriate for in vivo research, these MNPs should be monodispersion, superparamagnetism, and biocompatibility. Moreover, they should be easily conjugated with biomolecules.
Many techniques for MNP production are being developed. However, there are some problems regarding MNP properties which may affect their application in biological works. For example, it is difficult to control particles sizes via coprecipitation method, a conventional method to generate either $\mathrm{Fe}_{3} \mathrm{O}_{4}$ or $\gamma-\mathrm{Fe}_{2} \mathrm{O}_{3}$ nanoparticles by aqueous ferrous $\left(\mathrm{Fe}^{2+}\right)$ and ferric $\left(\mathrm{Fe}^{3+}\right)$ salt in base solution [6-8]. It was found that MNPs of this method had variation in size distributions. High-temperature decomposition of organic precursors is another technique used to generate MNPs with narrow size distribution and good crystallinity [9-11]. However, the disadvantages of this method are low magnetization per particle, and the organic agents are quite expensive [12]. In addition, MNPs obtained from both methods are not hydrophilic enough and have no proper $\mathrm{NH}_{2}$ functional group on their surface to be conjugated with biological materials for further being used as labeling reagents.

In this study, MNPs were synthesized using polyol method which polyalcohol was used as solvent and reducing 
TABLE 1: Size of amino-MNPs at different parameters.

\begin{tabular}{lcccc}
\hline Sample & \multicolumn{2}{c}{ Parameter } & $\begin{array}{c}\text { Size }(\mathrm{nm}): \\
\mathrm{NaOH}(\% \mathrm{w} / \mathrm{v})\end{array}$ & $\begin{array}{c}\text { Average size } \\
(\mathrm{nm})\end{array}$ \\
\hline $\mathrm{A}-1$ & 1.25 & 1 & $\mathrm{nd}$ & $\mathrm{nd}$ \\
$\mathrm{A}-2$ & 1.25 & 2 & $\mathrm{nd}$ & $\mathrm{nd}$ \\
$\mathrm{A}-3$ & 1.25 & 3 & $21<d<113$ & $47 \pm 20$ \\
$\mathrm{~A}-4$ & 1.25 & 4 & $15<d<53$ & $33 \pm 9$ \\
\hline $\mathrm{B}-1$ & 2.50 & 1 & $\mathrm{nd}$ & $\mathrm{nd}$ \\
$\mathrm{B}-2$ & 2.50 & 2 & $15<d<123$ & $45 \pm 21$ \\
$\mathrm{~B}-3$ & 2.50 & 3 & $23<d<107$ & $43 \pm 9$ \\
$\mathrm{~B}-4$ & 2.50 & 4 & $19<d<76$ & $41 \pm 12$ \\
\hline $\mathrm{C}-1$ & 3.75 & 1 & $\mathrm{nd}$ & $\mathrm{nd}$ \\
$\mathrm{C}-2$ & 3.75 & 2 & $15<d<69$ & $29 \pm 11$ \\
$\mathrm{C}-3$ & 3.75 & 3 & $14<d<92$ & $43 \pm 17$ \\
$\mathrm{C}-4$ & 3.75 & 4 & $15<d<69$ & $39 \pm 12$ \\
\hline
\end{tabular}

nd $=$ not determined .

agent. The advantage of this technique over other methods is that obtained MNPs are hydrophilic. However, most polyol methods [13-15] are carried out at very high temperature $\left(>200^{\circ} \mathrm{C}\right)$ and under inert gas atmosphere to prevent an oxidation reaction by $\mathrm{O}_{2}$ in the environment. Therefore, this work was conducted in an autoclave which provided lower temperature operation without any inert gas. Moreover, MNPs in this study were prepared to have an amino group on their particle surface within one step of synthesis.

\section{Experimental}

2.1. Materials. The reagents for amino-MNPs synthesis are Iron(III) chloride hexahydrate $\left(\mathrm{FeCl}_{3} \cdot 6 \mathrm{H}_{2} \mathrm{O}\right.$; Poch, Poland), sodium hydroxide $(\mathrm{NaOH}$; Rankem, India), sodium acetate $\left(\mathrm{CH}_{3} \mathrm{COONa}\right.$; Merck, Germany), ethylenediamine (Panreac, EU) and ethylene glycol (Unilab, Australia). Ethanol (95\%) and distilled water were used for washing amino-MNPs after the synthesis.

2.2. Apparatus. Autoclave (Sanyo Model MLS-3020, Japan) was used as a reactor for MNPs synthesis. Morphology and size of amino-MNPs were determined by Transmission Electron Microscope (TEM; JEOL Model JEM-1010, Japan). Scanning Electron Microscope with Energy Dispersive Spectrometer (SEM-EDS; JEOL Model JSM-6400, Japan) was used for elemental composition analysis. Structure of amino-MNPs was characterized by X-ray Diffractometer (XRD; Bruker AXS Model D8 Discover, Germany). Functional groups and bonds within MNPs were examined by Fourier Transformed Infrared (FT-IR) Spectrometer (Perkin Elmer Model Spectrum One, USA). Magnetic properties were characterized by vibrating sample magnetometer (VSM) developed by Department of Physics, Kasetsart University.

2.3. Preparation of MNPs. Amino-MNPs were prepared using polyol technique as described by Guo et al. [12] with some modification to attach an amine group onto the particle surface during the synthesis. Briefly, $2 \mathrm{~g}$ of $\mathrm{FeCl}_{3} \cdot 6 \mathrm{H}_{2} \mathrm{O}$ was added into $40 \mathrm{~mL}$ ethylene glycol and mixed until the solution was cleared yellow. Then, $6 \mathrm{~g}$ of $\mathrm{CH}_{3} \mathrm{COONa}$, varied amount of $\mathrm{NaOH}$ and $20 \mathrm{~mL}$ of ethylenediamine (source of amino group) were added, and the mixture was stirred for $30 \mathrm{~min}$. The mixed solution was further heated in an autoclave at $121^{\circ} \mathrm{C}, 105 \mathrm{kPa}$, for $2 \mathrm{~h}$ per cycle. After the reaction was completed, amino-MNPs were isolated by magnet and washed with distilled water and 95\% ethanol several times to remove the solvent. The amino-MNPs were dried, ground, and stored in a dry bottle.

The concentrations of $\mathrm{NaOH}(1.25,2.50$ and $3.75 \% \mathrm{w} / \mathrm{v})$ and the reaction time (1, 2, 3 and 4 cycles) were varied to study their effects on morphology of MNPs and the speed of MNP formation.

\section{Results and Discussion}

3.1. Morphology and Structure of MNPs. Amino-MNPs were prepared by polyol technique using $\mathrm{FeCl}_{3} \cdot 6 \mathrm{H}_{2} \mathrm{O}$ as a precursor of magnetic particles and ethylenediamine as an amino group source. The synthesis of amino-MNPs was conducted in an autoclave providing lower temperature without using any inert gas in the condition as compared with other methods $[16,17]$. A suitable condition for synthesis was studied by varying amount of $\mathrm{NaOH}$ from 1.25 to $3.75 \%$ w/v and reaction time from 1 to 4 cycles. Effects of these parameters on morphology and the size were determined as shown in Figure 1 and Table 1. However, samples A-1, A-2, B-1, and C-1 were not observed by TEM, because they did not response to magnet indicating that magnetic particles were not produced. Samples A-3 and B-2 showed irregular shape of particles and wide size distribution $(47 \pm 20$ and $45 \pm 21 \mathrm{~nm}$ ). Samples A-4 and C-2 showed quite uniform size of particles, but the shape of some particles was still uncertain $(33 \pm 9$ and $29 \pm 11 \mathrm{~nm})$. Samples B-3, B-4, C3 , and C-4 showed more uniform in size with cubic shape $(43 \pm 9,41 \pm 12,43 \pm 17$, and $39 \pm 12 \mathrm{~nm}$, resp.). From the overall results, MNPs from sample B-3 were selected for further characterization because of their shape and size and short reaction time.

For the formation of amino-MNPs, the results showed that the speed of MNP formation depends on the amount of $\mathrm{NaOH}$ in reactor. At $1.25 \% \mathrm{NaOH}$, the particles with magnetic properties were formed (responded to magnet) at 3 reaction cycles, while at $2.50 \%$ and $3.75 \% \mathrm{NaOH}$, the formation could be detected within 2 reaction cycles. Moreover, the morphology from TEM image at the same reaction times show the well-defined particles could form more quickly in the condition with higher amount of $\mathrm{NaOH}$. According to Guo et al. [12], they suggested that the size of MNPs could be controlled by adjusting amount of $\mathrm{NaOH}$. The larger amount of $\mathrm{NaOH}$ resulted in smaller and polydisperse particles because of too rapid particle formation. Because $\mathrm{NaOH}$ enhanced the transformation of EG to acetaldehyde [18], a strong reducing agent, it will accelerate the reduction of iron ion to form magnetite. 

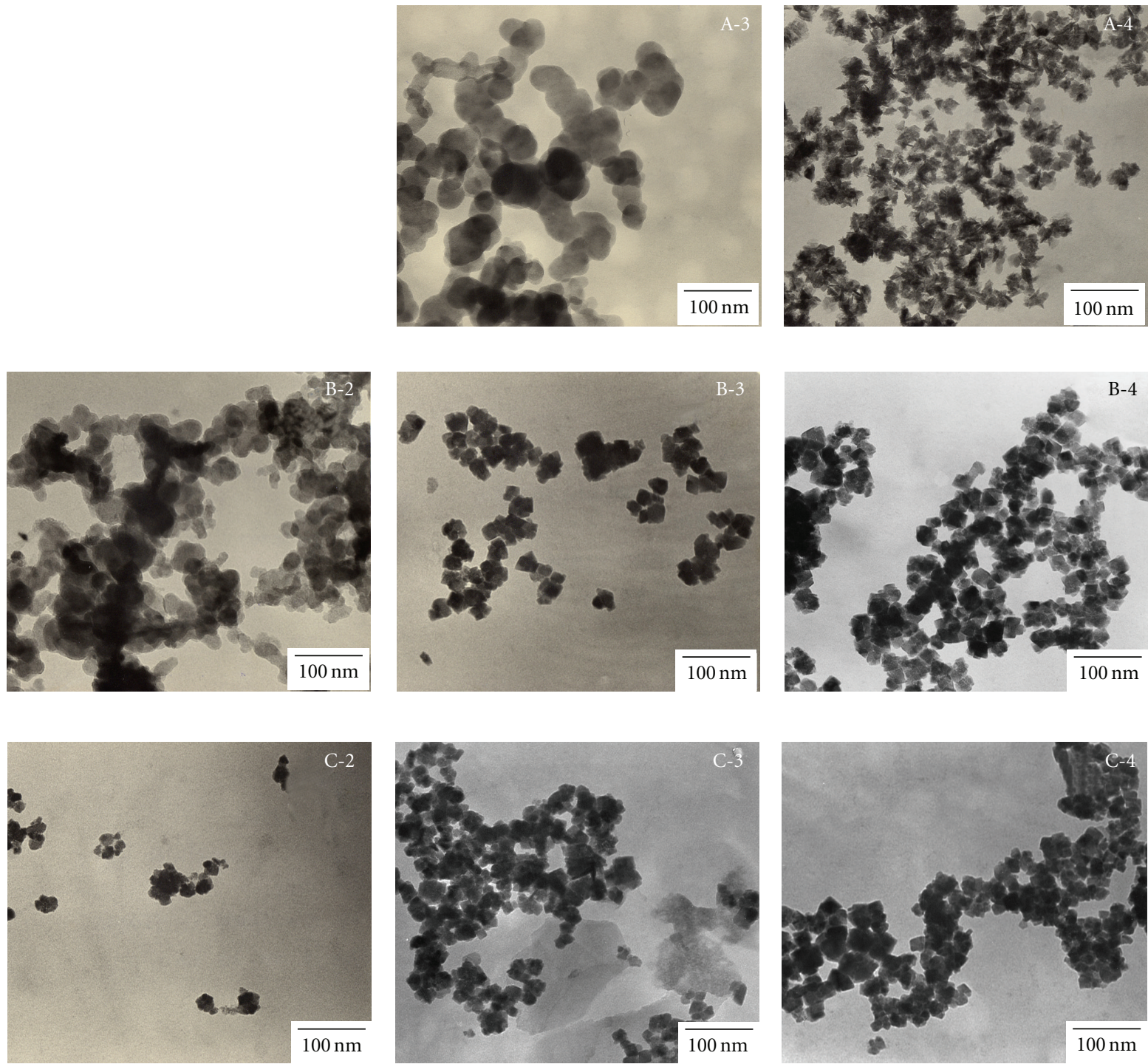

Figure 1: TEM images at 150000x showing the amino-MNPs prepared at various concentrations of NaOH with $2 \mathrm{~h}$ reaction cycles. Letters denote $\mathrm{NaOH}$ at $\mathrm{A}=1.25 \%, \mathrm{~B}=2.50 \%$ and $\mathrm{C}=3.75 \%$ while numbers indicate reaction cycles. The bar in each TEM image represents $100 \mathrm{~nm}$.

However, in this study, the size of MNPs at different $\mathrm{NaOH}$ did not differ significantly, but it could be concluded that amount of $\mathrm{NaOH}$ affected to the speed of magnetic particle formation.

The reaction time was also studied to understand the formation mechanism of amino-MNPs. At 1 cycle of reaction of all samples and 2 cycles of sample A, brown precipitate was formed in the reactors but with no reaction with magnet. It indicated magnetic particles had not occurred. At 2 reaction cycles of samples B and C and 3 reaction cycles of sample A, the precipitates turned to black color and could be attracted by permanent magnet indicating magnetic particles had been formed already. The TEM images at short reaction time showed that the particles were quite round and irregular shape, polydispersion and high size distribution. After the reaction time passed for 3 reaction cycles in samples $B$ and $C$ and 4 reaction cycles in sample $\mathrm{A}$, well-defined and lower size distribution particles were obtained (Figure 1; samples A-4, B-3 and C-3). When the reaction time extended to 4 cycles in samples B and C, the morphology and size of particles did not change significantly compared with that of the reaction time of 3 cycles.

Elemental components of MNP product (sample B-3) were characterized by SEM-EDS. The results showed that the major elements of amino-MNPs were $\mathrm{Fe}(42.87 \%$ atomic) and $\mathrm{O}(55.45 \%$ atomic). It confirmed that the MNP product was magnetite, because the atomic ratio of $\mathrm{Fe}: \mathrm{O}$ was about $3: 3.88$ which was similar to the theoretical atomic ratio of magnetite $(3: 4)$. Carbon was also detected but was lower than $1.68 \%$ atomic, indicating the existence of ethylenediamine molecules on particle surface.

XRD was used to characterize the structure. The XRD pattern result is shown in Figure 2. The peaks of aminoMNPs matched well with the XRD pattern of standard 


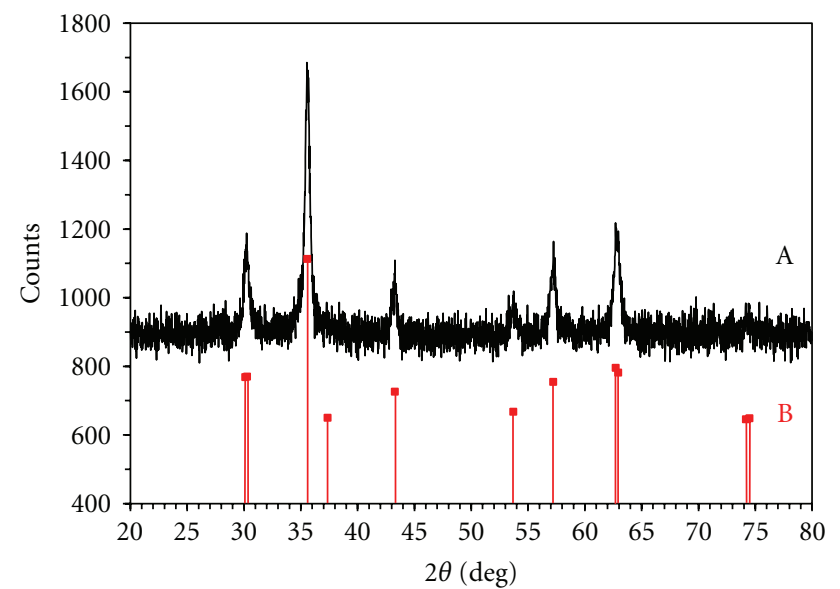

FIGURE 2: XRD pattern of amino-MNPs (A) and standard XRD pattern of face-centered cubic magnetite (B).

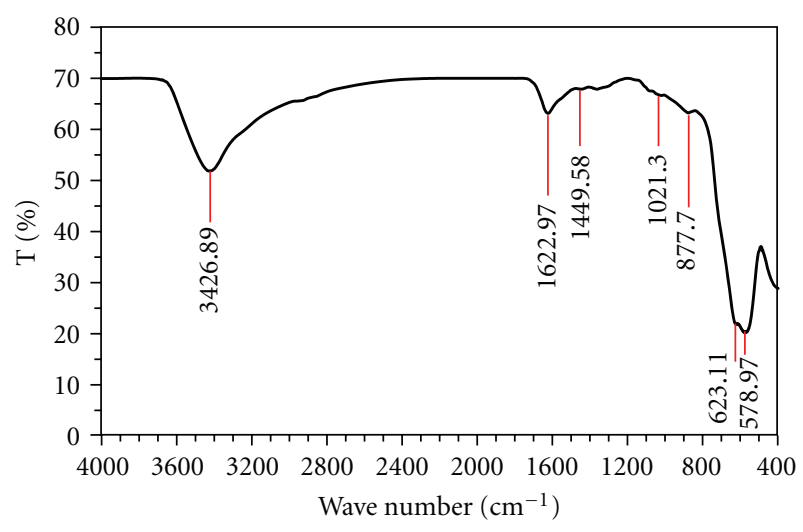

FIgURE 3: FT-IR spectrum of amino-MNPs.

magnetite (Figure 2(B)) from the database (JCPDS 0880315, ICSD collection code: 084611$)$ that can be indexed to the face-centered cubic crystalline structure with cell constant $a=8.375 \AA$. These results conformed to the EDS analysis and morphology of particle from a TEM image. No impurity phase was detected in the MNP product.

Generally, most polyol methods for producing magnetite particles [13-15] were conducted at very high temperature $\left(>200^{\circ} \mathrm{C}\right)$ and under inert gas to prevent oxidation of magnetite by $\mathrm{O}_{2}$ in the environment. However, the MNPs in this work were produced using autoclave as a reactor, operating at temperature of $121^{\circ} \mathrm{C}$, high pressure $(105 \mathrm{kPa})$, and without any inert gas. The results showed that the MNPs could be produced with good size and structure. This indicated that temperature lower than $200^{\circ} \mathrm{C}$ could be used to produce MNPs and that means less energy consumption as well. Although no inert gas was used in the synthesis, other iron oxide species except from magnetite were not detected. This could be due to the condition inside the autoclave. When it is heated to the boiling point of water, steam is generated, and it expels other gases including $\mathrm{O}_{2}$ from the autoclave, and this prevents the MNPs from oxidation. However, the effect of high pressure to the MNP synthesis was not cleared. To understand this effect, more investigations are required.

3.2. Functional Groups and Chemical Bonds of MNPs. The MNPs in this experiment were modified to attach an amino group onto their surface ready for the conjugation of any biomolecules. In order to examine the existence of amino group on particle surface, amino-MNPs were analyzed with FT-IR spectroscopy. Figure 3 shows the strong IR band of MNPs at 578.97 and $623.11 \mathrm{~cm}^{-1}$ referring to the $\mathrm{Fe}-\mathrm{O}$ bond split form the band at $570 \mathrm{~cm}^{-1}$ of bulk magnetite [19]. These results were probably due to the effect of very small size of MNPs. The band at 1622.97 and $3426.89 \mathrm{~cm}^{-1}$ refers to the $\mathrm{NH}_{2}$ bending of free $\mathrm{NH}_{2}$ group and $\mathrm{N}-\mathrm{H}$ stretching vibration, respectively, which is similar to previous reports $[19,20]$. Amino group on particle surface belongs to the ethylene diamine molecules which were a material for amino-MNP synthesis and believed that they were absorbed on MNP surface.

3.3. Magnetic Properties. Magnetization curves of aminoMNPs at room temperature are shown in Figure 4. The curves indicated that the MNPs were ferromagnetism and very close to complete superparamagnetism with a saturation magnetization (Ms) of about $48 \mathrm{emu} / \mathrm{g}$, remanence (Mr) of $1.7 \mathrm{emu} / \mathrm{g}$ and coercivity (Hc) of 23.5 Oe. Moreover, amino-MNPs were well dispersed in water and could be separated from the solution by the attraction of a magnet (Figure 5).

According to Liu et al. [21], magnetite particles will exhibit complete superparamagtetic properties when their size below $25 \mathrm{~nm}$, which is a critical size of magnetite. At this size, each particle has only one magnetic domain, and when a magnetization curve is plotted, the curve will intersect the zero point and has no remanence and coercivity. Although the MNPs produced in this work were not superparamagnetism because their size $(43 \mathrm{~nm})$ was larger than the critical size, their ferromagnetic properties were evident. Moreover, they could be well dispersed in aqueous solution and separated by magnetic force that were sufficient to be used in any biological applications [22, 23].

\section{Conclusion}

This study showed a facile technique for the synthesis of MNPs with amino group within a single step. Amino-MNPs with different size were prepared via polyol technique using autoclave as a reactor. The reaction could occur under lower temperature as compared to other reports. The results showed that the amount of $\mathrm{NaOH}$ had an effect on the speed of MNP formation. XRD and EDS analysis confirmed that the amino-MNPs were pure magnetite. FT-IR analysis showed the existence of amino group on particle which is necessary for conjugation with biomolecules when they were applied in biological applications. However, VSM showed 


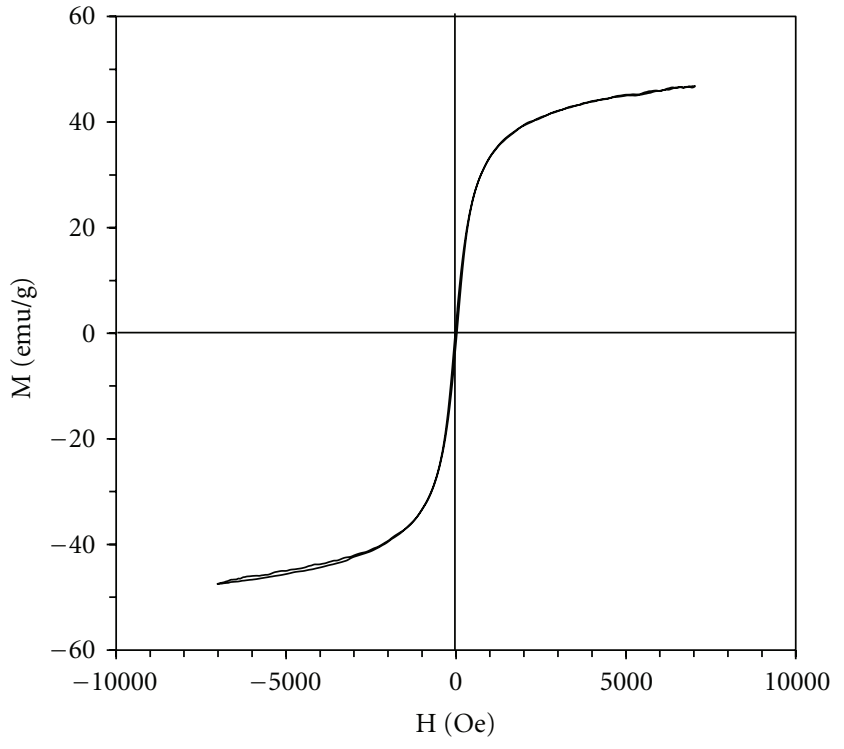

(a)

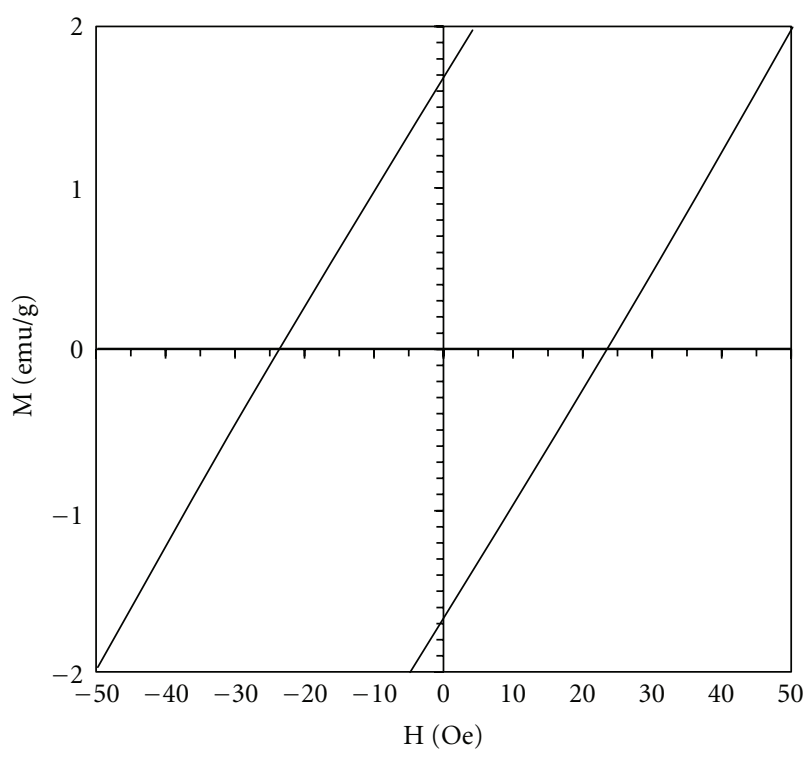

(b)

FIGURE 4: Magnetization curves of amino-MNPs (a) and hysteresis loop of magnetization curve (b).

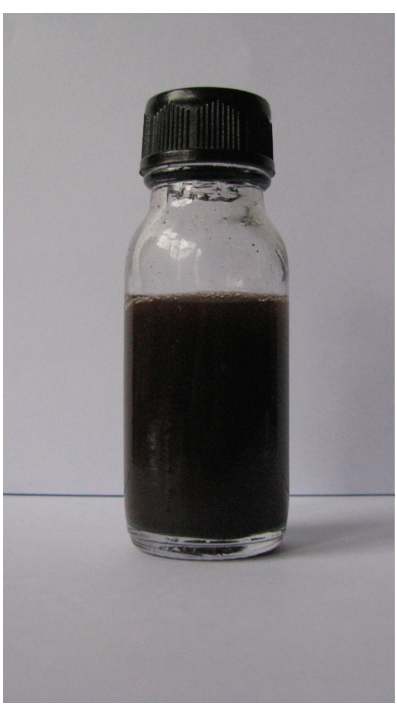

(a)

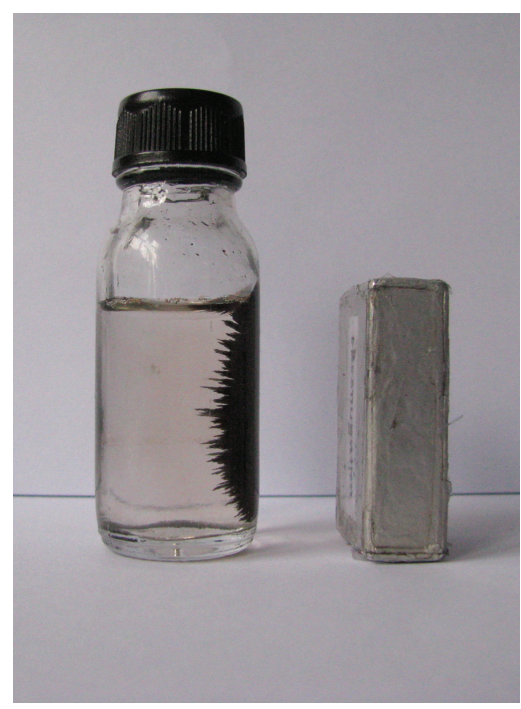

(b)

Figure 5: The amino-MNPs dispersed well in water and readily separated from the solution by the attraction to a magnet.

that the amino-MNPs were ferromagnetism and very close to superparamagnetism.

\section{Acknowledgments}

The authors thank Professor Dr. Pichet Limsuwan of KMUTT Department of Physics, and Assistent Professor Dr. Pongsakorn Jantaratana of the Department of Physics, Kasetsart University for providing VSM for magnetic property measurement in this work.

\section{References}

[1] A. Ito, Y. Kuga, H. Honda et al., "Magnetite nanoparticleloaded anti-HER2 immunoliposomes for combination of antibody therapy with hyperthermia," Cancer Letters, vol. 212, no. 2, pp. 167-175, 2004.

[2] U. Schillinger, T. Brill, C. Rudolph et al., "Advances in magnetofection-magnetically guided nucleic acid delivery," Journal of Magnetism and Magnetic Materials, vol. 293, no. 1, pp. 501-508, 2005.

[3] Y. Cheng, Y. Liu, J. Huang et al., "Combining biofunctional magnetic nanoparticles and ATP bioluminescence for rapid 
detection of Escherichia coli," Talanta, vol. 77, no. 4, pp. 1332 1336, 2009.

[4] D. Horák, M. Babič, P. Jendelová et al., "Effect of different magnetic nanoparticle coatings on the efficiency of stem cell labeling," Journal of Magnetism and Magnetic Materials, vol. 321, no. 10, pp. 1539-1547, 2009.

[5] J. Chomoucka, J. Drbohlavova, D. Huska, V. Adam, R. Kizek, and J. Hubalek, "Magnetic nanoparticles and targeted drug delivering," Pharmacological Research, vol. 62, no. 2, pp. 144$149,2010$.

[6] J. Chatterjee, Y. Haik, and C. J. Chen, "Size dependent magnetic properties of iron oxide nanoparticles," Journal of Magnetism and Magnetic Materials, vol. 257, no. 1, pp. 113-118, 2003.

[7] P. Sipos, "Manufacturing of size controlled magnetite nanoparticles potentially suitable for the preparation of aqueous magnetic fluids," Romanian Reports in Physics, vol. 58, no. 3, pp. 269-272, 2006.

[8] C. C. Hua, S. Zakaria, R. Farahiyan et al., "Size-controlled synthesis and characterization of $\mathrm{Fe}_{3} \mathrm{O}_{4}$ nanoparticles by chemical coprecipitation method," Sains Malaysiana, vol. 37, no. 4, pp. 389-394, 2008.

[9] T. Hyeon, S. S. Lee, J. Park, Y. Chung, and H. B. Na, "Synthesis of highly crystalline and monodisperse maghemite nanocrystallites without a size-selection process," Journal of the American Chemical Society, vol. 123, no. 51, pp. 12798$12801,2001$.

[10] S. Sun, H. Zeng, D. B. Robinson et al., "Monodisperse $\mathrm{MFe}_{2} \mathrm{O}_{4}$ ( $\mathrm{M}=\mathrm{Fe}, \mathrm{Co}, \mathrm{Mn}$ ) Nanoparticles," Journal of the American Chemical Society, vol. 126, no. 1, pp. 273-279, 2004.

[11] L. M. Bronstein, X. Huang, J. Retrum et al., "Influence of iron oleate complex structure on iron oxide nanoparticle formation," Chemistry of Materials, vol. 19, no. 15, pp. 36243632, 2007.

[12] S. Guo, D. Li, L. Zhang, J. Li, and E. Wang, "Monodisperse mesoporous superparamagnetic single-crystal magnetite nanoparticles for drug delivery," Biomaterials, vol. 30, no. 10, pp. 1881-1889, 2009.

[13] H. L. Liu, S. P. Ko, J. H. Wu et al., "One-pot polyol synthesis of monosize PVP-coated sub-5 $\mathrm{nm} \mathrm{Fe}_{3} \mathrm{O}_{4}$ nanoparticles for biomedical applications," Journal of Magnetism and Magnetic Materials, vol. 310, no. 2, pp. e815-e817, 2007.

[14] W. Cai and J. Wan, "Facile synthesis of superparamagnetic magnetite nanoparticles in liquid polyols," Journal of Colloid and Interface Science, vol. 305, no. 2, pp. 366-370, 2007.

[15] J. Ding, K. Tao, J. Li, S. Song, and K. Sun, "Cell-specific cytotoxicity of dextran-stabilized magnetite nanoparticles," Colloids and Surfaces B: Biointerfaces, vol. 79, no. 1, pp. 184-190, 2010.

[16] D. Zhang, J. Zheng, and Z. Tong, "Fabrication and characterisation of $\mathrm{Fe}_{3} \mathrm{O}_{4}$ nanowires via an ethylenediamine-assisted route," Journal of Experimental Nanoscience, vol. 5, no. 2, pp. $162-168,2010$.

[17] K. C. Barick, M. Aslam, P. V. Prasad, V. P. Dravid, and D. Bahadur, "Nanoscale assembly of amine-functionalized colloidal iron oxide," Journal of Magnetism and Magnetic Materials, vol. 321, no. 10, pp. 1529-1532, 2009.

[18] R. J. Joseyphus, K. Shinoda, D. Kodama, and B. Jeyadevan, "Size controlled Fe nanoparticles through polyol process and their magnetic properties," Materials Chemistry and Physics, vol. 123, no. 2-3, pp. 487-493, 2010.

[19] M. Yamaura, R. L. Camilo, L. C. Sampaio, M. A. Macêdo, M. Nakamura, and H. E. Toma, "Preparation and characterization of (3-aminopropyl)triethoxysilane-coated magnetite nanoparticles," Journal of Magnetism and Magnetic Materials, vol. 279, no. 2-3, pp. 210-217, 2004.

[20] L. D. White and C. P. Tripp, "Reaction of (3-aminopropyl)dimethylethoxysilane with amine catalysts on silica surfaces," Journal of Colloid and Interface Science, vol. 232, no. 2, pp. 400-407, 2000.

[21] X. Liu, M. D. Kaminski, Y. Guan, H. Chen, H. Liu, and A. J. Rosengart, "Preparation and characterization of hydrophobic superparamagnetic magnetite gel," Journal of Magnetism and Magnetic Materials, vol. 306, no. 2, pp. 248-253, 2006.

[22] R. S. Molday and D. Mackenzie, "Immunospecific ferromagnetic iron-dextran reagents for the labeling and magnetic separation of cells," Journal of Immunological Methods, vol. 52, no. 3, pp. 353-367, 1982.

[23] G. Pappert, M. Rieger, R. Niessner, and M. Seidel, "Immunomagnetic nanoparticle-based sandwich chemiluminescenceELISA for the enrichment and quantification of E. coli," Microchimica Acta, vol. 168, no. 1-2, pp. 1-8, 2010. 

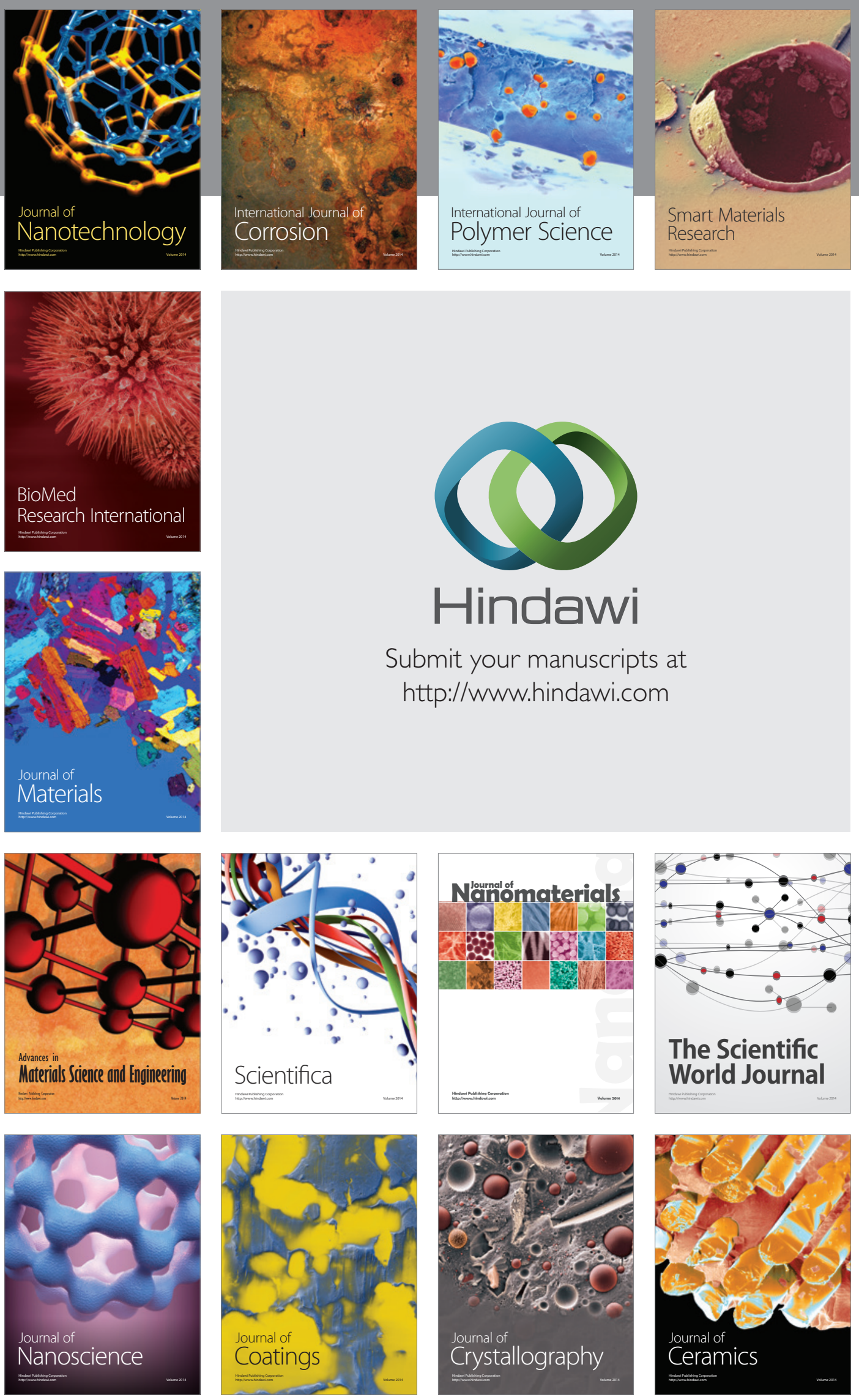

The Scientific World Journal

Submit your manuscripts at

http://www.hindawi.com

\section{World Journal}

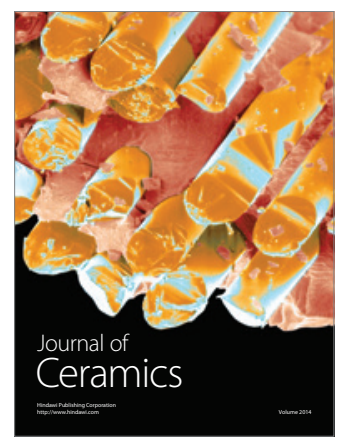

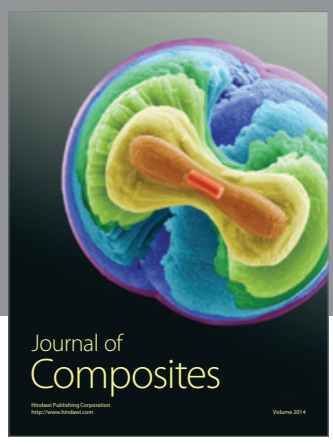
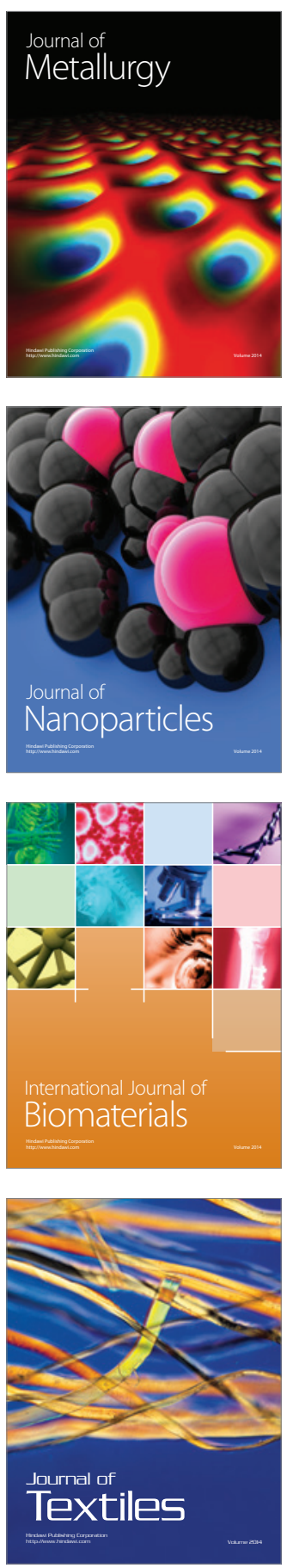